ANL/ET/CP-9366

\title{
PROPERTIES OF TIN and TIN DEPOSITED BY CVD ON GRAPHITE FOR PYROCHEMICAL APPLICATIONS*
}

P. S. Maiya and B. M. Moon $\dagger$

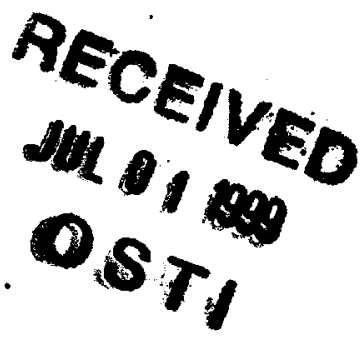

Energy Technology Division

Argonne National Laboratory

Argonne, Illinois 60439

† SGL Carbon Corporation

9224 King Arthur DR.

Dallas, TX 75247

\begin{abstract}
The submitted manuscript has been created by the University of Chicago as Operator of Argonne National Laboratory ("Argonne") under Contract No. W-31-109-ENG-38 with the U.S. Department of Energy. The U.S. Government retains for itseff, and others acting on its behalf, a paid-up, nonexclusive. irrevocable worldwide license in said article to reproduce, prepare derivative works, distribute copies to the public, and perform publicly and display publicly, by or on behalf of the Government.
\end{abstract}

November 1997

For presentation at Symposium W: Chemical Aspects of Electronic Ceramics Processing, Materials Research Society 1997 Fall Meeting, December 1-5, 1997, Boston.

*Work supported by the U.S. Department of Energy, Nuclear Energy Research Program, under Contract W-31-109-Eng-38. 


\section{DISCLAIMER}

This report was prepared as an account of work sponsored by an agency of the United States Government. Neither the United States Government nor any agency thereof, nor any of their employees, make any warranty, express or implied, or assumes any legal liability or responsibility for the accuracy, completeness, or usefulness of any information, apparatus, product, or process disclosed, or represents that its use would not infringe privately owned rights. Reference herein to any specific commercial product, process, or service by trade name, trademark, manufacturer, or otherwise does not necessarily constitute or imply its endorsement, recommendation, or favoring by the United States Government or any agency thereof. The views and opinions of authors expressed herein do not necessarily state or reflect those of the United States Government or any agency thereof. 


\section{DISCLAIMER}

Portions of this document may be illegible in electronic image products. Images are produced from the best available original document. 


\section{PROPERTIES OF TIN AND TIN DEPOSITED BY CVD ON GRAPHITE FOR}

PYROCHEMICAL APPLICATIONS

P. S. Maiya* and B. M. Moon ${ }^{* *}$

*Energy Technology Division, Argonne National Laboratory, Argonne, IL 60439, subraya_maiya@qmgate.anl.gov

**SGL Carbon Corporation, Dallas, 75247

\section{ABSTRACT}

High-density $\mathrm{TiN}$ ( $>98 \%$ of theoretical) has been prepared by hot pressing TiN powder with $2-4$ wt. $\% \mathrm{Li}_{2} \mathrm{CO}_{3}$ at temperatures between $1150-1550^{\circ} \mathrm{C}$ and pressures of $\approx 40-50 \mathrm{MPa}$. The $\mathrm{Li}_{2} \mathrm{CO}_{3}$ served as a fugitive sintering aid, enabling attainment of high density at low temperatures without adversely affecting the inherently good properties. Variation in processing variables and TiN powder characteristics resulted in material with various porosities. Measurement of mechanical properties such as flexural strength and fracture toughness showed that the highdensity material has mechanical properties that are superior to those of several oxide ceramics. We have also quantified the effects of porosity on mechanical properties. In addition, adhesion and chemical stability tests were used to investigate graphite coated with $\mathrm{TiN}$ by chemical vapor deposition CVD). Pin-pull tests were used to determine coating adhesion and failure stresses were analyzed by Weibull statistics. All pin-pull tests resulted in fracture of the graphite substrate, rather than separation at the TiN/graphite interface. The data showed a good fit to the two-parameter Weibull expression, with a failure strength of $16.4 \mathrm{MPa}$ and Weibull modulus of 9.3. Both the high-density TiN and the TiN coating on the graphite were exposed to a corrosive molten salt $\mathrm{CaCl}_{2}-7$ wt. $\% \mathrm{CaO}$ and a liquid metal alloy $(\mathrm{Zn}-10 \mathrm{wt} . \% \mathrm{Mg})$ at $800^{\circ} \mathrm{C}$ for $168 \mathrm{~h}$ to determine chemical interactions. No reaction was detected by scanning electron microscopy (SEM) or energy-dispersive X-ray (EDX) analysis. Thus, graphite coated with TiN by CVD combines the thermodynamic stability of TiN when exposed to reactive molten metals and salts, with the excellent machinability of graphite, and hence is promising for use in container vessels for pyrochemical processing of certain rare-earth and nuclear metals, where chemical inertness and good matching of thermal expansion coefficients are required.

\section{INTRODUCTION}

Pyrochemical processing of certain nuclear metals is based on the use of highly corrosive molten $\mathrm{CaCl}_{2}$ and liquid metal alloys of $\mathrm{Zn}$ and $\mathrm{Mg}$ at temperatures of $500-900^{\circ} \mathrm{C}$ [1]. Moreover, certain rare-earth metals are produced commercialy by electrolysis of chlorides dissolved in alkali or alkaline earth melts [2]. TiN is considered an attractive container material for these applications due to its good thermodynamic stability. Although preparation of high-density bulk TiN by sintering with fugitive sintering aids such as $\mathrm{Li}_{2} \mathrm{CO}_{3}$ and $\mathrm{LiF}$ is possible (as this study shows), fabrication of large process vessels requires considerable developmental work. However, the chemical inertness of TiN to reactive molten metals and salts can be utilized by coating graphite with TiN by chemical vapor deposition (CVD). Graphite can be easily fabricated into containers and is stable in molten salts, but reacts with nuclear metals to form insoluble carbides and hence needs protection. The thermal expansion coefficients of TiN and graphite are similar, resulting in good thermal shock resistance.

Considerations of both thermodynamic stability and thermal shock resistance show that TiN is a promising container material for pyrochemical applications. The standard free energies of formation of selected oxides, carbides, and nitrides can be found in standard references $[3,4]$. Oxides are not acceptable because of dissolution and reduction reactions [5,6], but TiN and TiC are more stable than the corresponding transuranic compounds and calcium and lithium compounds. In addition, both $\mathrm{TiN}$ and $\mathrm{TiC}$ are attractive because of their superior thermal shock resistance, compared to several oxide ceramics. Thermal shock resistance is related to several mechanical and physical properties; e.g., materials should have high fracture strength so that thermal stress does not exceed fracture strength. High fracture strength also requires that the material not be too 
porous because higher porosity results in lower strength and also makes the material unsuitable for containing molten salt and liquid metal alloys. In addition, we require the material to have high fracture strength in order to sustain a large number of thermal cycles before cracks become critical; the material should also have a low elastic modulus to minimize thermal stress.

Several oxides can be fabricated from powder to nearly theoretical densities by hot pressing with small amounts of fugitive sintering aids such as $\mathrm{Li}_{2} \mathrm{CO}_{3}$ or $\mathrm{LiF}[7,8]$.

This paper is concerned with the preparation and properties of TiN disks by hot pressing with and without $\mathrm{Li}_{2} \mathrm{CO}_{3}$ together with the coating of graphite by TiN through CVD and evaluation of mechanical properties. The chemical stability of high-density TiN and graphite coated with TiN by CVD was investigated by exposure to reactive molten salt and liquid metal alloys.

\section{EXPERIMENTAL PROCEDURE}

TiN Disks: Hot pressing of TiN powder containing controlled amounts of $\mathrm{Li}_{2} \mathrm{O}_{3}$ was hot pressed to determine the optimal quantity of the sintering aid required for densification. To establish the appropriate amount of sintering aid, TiN powder was prepared by mixing $20 \%$ of fine TiN powder ( $99.8 \%$ purity with particle sizes of $2-5 \mu \mathrm{m}$ obtained from Johnson Matthey Catalog Co.) with $80 \%$ of coarser $(>25-30 \mu \mathrm{m})$ TiN powder (obtained from Atomergic Chemetals Corp.). The mixture was then processed with a known amount of $\mathrm{Li}_{2} \mathrm{CO}_{3}$ (Baker analyzed grade reagent) in stearic acid and xylene. The mixture was stirred continuously on a hot plate until all xylene was evaporated. The mixture was then dried in an oven at $80^{\circ} \mathrm{C}$ for $20 \mathrm{~h}$, followed by crushing in an agate mortar and pestle until all the powder passed through a 100-mesh screen. Several batches of powder were prepared with $0,0.5,2$, and $4 \mathrm{wt} . \%$ of $\mathrm{Li}_{2} \mathrm{CO}_{3}$ and hot pressed in a graphite die at elevated temperatures.

The die assembly for pressing the powder was lubricated with boron-nitride slip. The bottom punch was inserted into the die, and a piece of paper (same diameter as that of the punch $\approx 40.6 \mathrm{~mm}$ ) was placed on the top of punch. TiN powder, with or without the sintering aid, was poured, followed by a graphite spacer, another paper, and a graphite spacer. This procedure was repeated to obtain four TiN disks, as shown schematically in Fig. 1 (paper separating the spacer and powder is not shown). The powder in the die was then cold pressed to $40 \mathrm{MPa}$ in increments of $10 \mathrm{MPa}$. The assembly was removed from the hydraulic press, wrapped in carbon felt, and placed inside the hot press. Hot pressing was done at $1260^{\circ} \mathrm{C}$ for $1 \mathrm{~h}$ and a pressure of $50 \mathrm{MPa}$ in continuously flowing $\mathrm{N}_{2}$. After the chamber was cooled, the disks were removed from the die assembly and several rectagular bar specimens ( $\approx 35 \mathrm{~mm}$ length $\times 5 \mathrm{~mm}$ width $\times 4 \mathrm{~mm}$ thickness) were cut from the disks for characterization of physical and mechanical properties. Hot pressing of TiN with various amounts of $\mathrm{Li}_{2} \mathrm{CO}_{3}$ was also done at $1520^{\circ} \mathrm{C}$ to determine the effect of temperature on densification.

Density measurements were made by the conventional methods. Flexural strength was measured in a four-point-bending mode with an outer span of $19 \mathrm{~mm}$, and inner loading span of $9.5 \mathrm{~mm}$, and crosshead speed of $0.13 \mathrm{~cm} / \mathrm{min}$ in an Instron machine. Elastic properties such as Young's modulus, shear modulus, and Poisson ratio were determined from measurements of the longitudinal and shear sound velocities by the pulse-echo technique [9]. Fracture toughness was measured by a single-edge notch method [10]. Single-edge notches $(\approx 0.73-\mathrm{mm}$ depth) was produced on several rectangular specimens $(34 \times 4.6 \times 3.6 \mathrm{~mm})$ by an electrical discharge machine that used a copper wire.

Several of the rectangular bar specimens were used to study thermal-shock behavior. Approximately four specimens were heated in an air furnace for $30 \mathrm{~min}$ at an elevated temperature $\left(100-600^{\circ} \mathrm{C}\right)$ to achieve steady state. The bars were then quenched in water at room temperature, removed from the water, dried, and tested for flexural strength. 
In this study, various porosities were achieved by varying the hot-pressing parameters such as temperature and pressure, and by hot pressing with and without sintering aids. The various properties of specimens with different porosities were measured to establish correlations.

TiN-Coated Graphite: Fabrication of high-density TiN crucibles for pyrochemical applications requires considerable development work to identify the optimal processing variables and sintering conditions. Attempts to prepare TiN crucibles by cold pressing TiN powder with sintering aid $\left(\mathrm{Li}_{2} \mathrm{CO}_{3}\right)$ and sintering based on procedures described earlier [11] and by slip casting followed by sintering, were not successful. Graphite crucibles, however, can be fabricated into intricate large shapes but need protective coatings when used with certain carbide-forming nuclear metals. Therefore, in our initial study, graphite plates coated with TiN by CVD were considered for evaluation of adhesion and strength.

High-purity (AI6) isostatically pressed fine-grained graphite plates (51 x 25.4 x $6.4 \mathrm{~mm}$ ) were used for CVD coating with TiN. The thermal expansion coefficient of graphite is comparable to that of TiN. Fabrication and coating were done at SGL Carbon Corporation, Dallas, TX. In CVD, precursor gases decompose upon contact with a heated specimen, leaving behind a coating of the desired compound. For the TiN coating, an $\mathrm{N}_{2} / \mathrm{H}_{2}$ carrier gas mixture was used with a $\mathrm{TiCl}_{4}$ precursor. The gas was allowed to react with the plates at $1000^{\circ} \mathrm{C}$ at atmospheric pressure; coating times were typically $45 \mathrm{~min}$ to $1 \mathrm{~h}$, after a 30 min preannealing in $\mathrm{H}_{2}$. Coating thickness of TiN was $\approx 10 \mu \mathrm{m}$. Prior to coating, the graphite was purified by annealing in flowing $\mathrm{N}_{2}$ at $2000^{\circ} \mathrm{C}$ for $1 \mathrm{~h}$, followed by addition of flowing $\mathrm{Cl}_{2}$ to the gas stream for $10 \mathrm{~h}$.

Adhesion studies of TiN to graphite used the pin-pull method [12]. Aluminum pins or studs were bonded with epoxy to the coating to be tested. The cured epoxy has a strength of $\approx 70 \mathrm{MPa}$, significantly greater than the graphite strength of $\approx 39 \mathrm{MPa}$. The pins were pulled with increasing force normal to the substrate until separation occurred (Fig. 2). The failure stress is taken to be the force required to pull the coating from the substrate divided by the area of the pin.

The pin-pull tests were performed with a commercial pull-testing machine (Sebastian V). Before testing, the specimen was cleaned with a 9:1 hexane/toluene mixture in an ultrasonic bath for $1 \mathrm{~h}$ followed by rinsing in hexane and final cleaning with acetone. Aluminum pins $(2.69 \mathrm{~mm}$ head diameter) were bonded to the TiN surface with an epoxy that was cured for $\approx 30 \mathrm{~min}$ at $150^{\circ} \mathrm{C}$.

Chemical Stability Tests: The chemical stability of the high-density TiN and the TiN-coated graphite was studied in two corrosive environments: molten salt $\left(\mathrm{CaCl}_{2}-7 \mathrm{wt} . \% \mathrm{CaO}\right)$ and molten salt saturated with $\mathrm{Ca}$ to which was added an equal amount of $\mathrm{Zn}-10 \mathrm{wt}$.\% $\mathrm{Mg}$ melt. The liquid $\mathrm{Zn}-10 \mathrm{wt} . \% \mathrm{Mg}$ formed a bimetallic melt with the salt. Specimens were placed in graphite crucibles (graphite is inert to both molten salt and $\mathrm{Zn}-10 \mathrm{wt} . \% \mathrm{Mg}$ ), and appropriate quantities of molten salt, or molten salt + liquid metal, were loaded into the crucible so that at least $2 / 3$ of the specimen was immersed. The crucible was then sealed under helium in a stainless steel specimen bomb and annealed in a muffle furnace at $800^{\circ} \mathrm{C}$ for $168 \mathrm{~h}$. After exposure, the specimens were weighed and cross-sectioned for examination by scanning electron microscopy (SEM) and energydispersive X-ray (EDX) analysis.

\section{RESULTS AND DISCUSSION}

The effect of the quantity of $\mathrm{Li}_{2} \mathrm{CO}_{3}$ added to the powder (before hot pressing) on the density of TiN at two temperatures is shown in Fig. 3. The sintering aid has a more pronounced effect at the lower temperature than at the higher. In both cases, the amount of sintering aid in excess of 2 wt.\% does not appear to significantly affect densification. Analysis of TiN by inductively coupled plasma-atomic emission spectroscopy (ICP-AES) indicated that most of the sintering aid evaporated during hot pressing at elevated temperatures. The influence of sintering aid quantity on microstructure at $1260^{\circ} \mathrm{C}$, as examined by SEM, is shown in Fig. 3. Density close to $99 \%$ of 
theoretical can be achieved by addition of sintering aid and hot pressing at appropriate temperature and pressure.

Measurement of elastic and mechanical properties of TiN with various porosities show that lowering the porosity of the material results in higher strength and higher elastic moduli. Porosity dependence of strength and elastic properties is generally represented by several empirical equations. The dependence of Young's modulus $E$, shear modulus $G$, and strength $\sigma$ are represented by the following relationships [13]:

$$
\begin{aligned}
& E=E_{0}(1-p)^{\mathrm{m} 2} \\
& G=G_{0}(1-p)^{\mathrm{m} 2} \\
& \sigma=\sigma_{0}(1-p)^{\mathrm{m} 3},
\end{aligned}
$$

where $E_{0}, G_{0}, \sigma_{0}, \mathrm{~m} 1, \mathrm{~m} 2$, and $\mathrm{m} 3$ are constants. These correlations satisfy the boundary conditions $E=0, G=0$, and $\sigma=0$ at $p=1$. When $p=0$, we obtain properties of the material with $100 \%$ of theoretical density. Figures 4-6 show that our data on dependence of Young's modulus, shear modulus, and flexural strength on porosity are represented by Eqs. 1-3 and these relationships, although empirical, are useful in predicting the properties of porous and dense ceramics.

Fracture toughness, $\mathrm{K}_{\mathrm{Ic}}$, value for the high-density material ( $96 \%$ of theoretical density) is $4.3 \pm 0.34 \mathrm{MPa} . \mathrm{m}^{1 / 2}$, approximately a factor of 2 higher than the values we have measured for some dense oxide ceramics such as $\mathrm{MgO}, \mathrm{Y}_{2} \mathrm{O}_{3}$, and $\mathrm{Ca}_{3} \mathrm{Ti}_{2} \mathrm{O}_{7}$.

Thermal-shock resistance is related to several mechanical and physical properties. Hasselman [14] has proposed thermal-shock resistance parameters for various conditions. One simplified parameter, a measure of resistance to crack initiation, is $\mathrm{R}^{\prime}$, which equals $\sigma \kappa / \mathrm{E} \alpha$, where $\sigma$ is fracture strength, $K$ is thermal conductivity, $E$ is Young's modulus, and $\alpha$ is the coefficient of thermal expansion. Higher values of $R^{\prime}$ are associated with greater resistance to crack initiation under thermal shock. Using the properties published in the literature [15-19], together with properties we measured, we computed R' for several selected materials at $1000 \mathrm{~K}$. These calculations showed that the materials in order of decreasing thermal-shock resistance are $\mathrm{TiC}, 532 \mathrm{~N}, \mathrm{TiN}, \mathrm{AlN}, \mathrm{BeO}, \mathrm{NbC}, \mathrm{ZrC}, \mathrm{TaC}$, and $\mathrm{MgO}$. In this list, the material designated $532 \mathrm{~N}$ is a nitrided $\mathrm{Nb}$-based alloy containing $30 \mathrm{wt} . \%$ Ti and $20 \mathrm{wt} \% \mathrm{~W}$ (TRIBOCOR 532N) [19]. However, despite its good thermal shock resistance, $532 \mathrm{~N}$ is not chemically stable in molten salt/metal environments and hence both $\mathrm{TiC}$ and $\mathrm{TiN}$ appear to have the best thermal shock resistance of the materials we considered.

Thermal-shock resistance of $\mathrm{TiN}$ was investigated by the water-quench method and showed that degradation in flexural strength occurred at $\Delta \mathrm{T}$ (quenching temperature difference) $\approx 125 \mathrm{~K}$, which is similar to that of several oxide ceramics such as $\mathrm{Ca}_{3} \mathrm{Ti}_{2} \mathrm{O}_{7}$ [6], but greater strength is retained by $\mathrm{TiN}$ than by $\mathrm{Ca}_{3} \mathrm{Ti}_{2} \mathrm{O}_{7}$ in these water-quench experiments. Also, the remaining strength at $\Delta \mathrm{T}>150 \mathrm{~K}$ remained nearly constant for $\mathrm{TiN}$, whereas the strength of $\mathrm{Ca}_{3} \mathrm{Ti}_{2} \mathrm{O}_{7}$ decreased rapidly to values approaching zero, suggesting a higher thermal shock resistance for TiN. Note that in this type of severe testing, only significant differences in thermal shock resistance can be determined.

The pin-pull tests performed on TiN-coated graphite showed that failure occurred in the bulk graphite in all cases; the coating/graphite interface remained intact. Failure stress data from the TiN-coated graphite exhibited scatter. It is therefore meaningful to analyze such data in the manner of Weibull $[20,21]$, a common method used extensively to analyze fracture behavior of 
engineering ceramics. If $\mathrm{P}(\sigma)$ is the probability that a tested graphite coating will support a stress $\sigma$, for multiple tests the probability of failue can be estimated as

$$
\mathrm{P}(\sigma)=\mathrm{n}_{\sigma} /(\mathrm{N}+1)
$$

where $n_{\sigma}$ is the rank of a specimen that failed at stress $\sigma$ when the data are sorted in increasing order of $\sigma$, and $\mathrm{N}$ is the total number of tests. The Weibull equation is then written as

$$
\mathrm{P}(\sigma)=1-\exp \left\{-\left[\left(\sigma-\sigma_{u}\right) / \sigma_{0}\right]^{\mathrm{m}}\right\},
$$

where $\sigma_{4}$ can be considered the threshold stress below which fracture does not occur, $\sigma_{0}$ is a characteristic stress that is a measure of the strength of the system, and $\mathrm{m}$ is the Weibull modulus that indicates the variability of measured strength. The lower the modulus, the greater the variability of strength. For brittle fracture, $\sigma_{u}$ is usually taken to be zero. Thus, $\sigma_{0}$ is the stress at which the probability of failure is $63.2 \%$. The characteristic stress $\sigma_{0}$ and Weibull modulus $\mathrm{m}$ were determined by performing a computer fit of the values of $P(\sigma)$ and $\sigma$ to the Weibull equation (Eq. 5) with the assumption that $\sigma_{u}$ is zero.

Figure 7 shows a plot of the probability of failure vs. failure stress for TiN-coated graphite; a good fit of the data to the Weibull equation was found. Characteristic stress is $17.6 \mathrm{MPa}$ and the Weibull modulus is 9.3. Instead of using Eq. 3, some investigators [22] have proposed $\mathrm{P}(\sigma)=\left(\mathrm{n}_{\sigma}-0.5\right) / \mathrm{N}$ to estimate the probability of failure. No significant differences were obtained when this expression was used.

Thermal cycling experiments were not performed on TiN-coated graphite in our study. Other investigators [23] have shown that CVD coatings of $\mathrm{TiC}$ and $\mathrm{TiB}_{2}$ on graphite have performed well under thermally cycled conditions. The good thermal-shock resistance is attributed to the good match of the thermal expansion coefficients of graphite and $\mathrm{TiC}$ or $\mathrm{TiB}_{2}$.

After $168 \mathrm{~h}$ exposure at $800^{\circ} \mathrm{C}$, visual examination of both TiN (high-density) and TiNcoated graphite, showed that coatings reacted neither with the molten salt nor liquid metal. These observations are substantiated by ICP-AES analysis of the salt and metal environments. Weight measurements before and after exposure indicated negligible weight change $( \pm 0.01 \%)$. The specimens were then cross-sectioned, mounted, and metallographically prepared by grinding on silicon carbide paper and polishing on diamond paper (the latter is preferred to paste in order to retain the coating edges) for examination by SEM and EDX analysis. SEM examination of the cross-sectioned TiN-coated graphite did not show any evidence of chemical interactions between the TiN coating and molten salt, nor was $\mathrm{Ca}$ detected in the coating (Fig. 8a). Figure 8b shows similar results in molten salt $+\mathrm{Zn}-10 \mathrm{wt} . \% \mathrm{Mg}$. Figure 8 shows that the coating adhered well to the substrate even in the rounded edges of the specimen. No discontinuity of coating was seen along the interface at either low or high magnification. Thus, TiN coating on graphite, in addition to displaying good adherence, is chemically stable in corrosive and reducing molten salt and liquid metal alloy baths. These results are consistent with the chemical analysis of salt by ICP-AES.

\section{SUMMARY AND CONCLUSIONS}

TiN has been identified as good container material for pyrochemical processing, based on its thermodynamic stability and thermal shock resistance. Density $>96 \%$ of theoretical has been achieved in TiN prepared by hot pressing with the use of the sintering aid $\mathrm{Li}_{2} \mathrm{CO}_{3}$. An optimal amount of $2 \mathrm{wt} . \%$ of sintering aid was found to promote densification at $1260^{\circ} \mathrm{C}$ during hot pressing. Properties have been determined for several porous and high-density TiN disks prepared with different processing variables, and correlations have been described between properties and porosity. These relationships, although empirical, facilitate prediction of strength and elastic modulus of TiN with different porosities. The TiN has better thermal-shock resistance than the oxides previously investigated by water-quench experiments. 
Adhesion testing was used to investigate graphite coated with TiN by chemical vapor deposition; the coatings adhered strongly to the graphite and fracture occurred only in the bulk graphite, not at the TiN/graphite interface. The data showed a good fit to the two-parameter Weibull expression, with failure strength of $16.4 \mathrm{MPa}$ and Weibull modulus of 9.3.

No reaction of $\mathrm{TiN}$ or $\mathrm{TiN}$ coating on graphite with the aggressive molten salt $\mathrm{CaCl}_{2}-7 \mathrm{wt}$.\% $\mathrm{CaO}$ or with molten salt saturated with $\mathrm{Ca}+$ liquid $\mathrm{Zn}-10 \mathrm{wt} . \% \mathrm{Mg}$, at $800^{\circ} \mathrm{C} / 168 \mathrm{~h}$ could be detected by either scanning electron microscopy and energy-dispersive X-ray analysis or by chemical analysis.

\section{ACKNOWLEDGMENTS}

We are grateful to D. E. Busch, S. F. Zentack, and S. M. McDeavitt for their assistance with experiments. This work was supported by the U.S. Department of Energy, Nuclear Energy Research and Development Program, under Contract W-31-109-Eng-38.

\section{REFERENCES}

1. R. D. Pierce, T. R. Johnson, C. C. McPheeters, and J. J. Laidler, J. Metals, 45, p. 40 (1993).

2. I. N. Ross, The Metallurgical and Materials Technologist, p. 311 (July 1974).

3. JANF Thermochemical Tables, J. of Physical and Chemical Reference Data, 14, Parts I and II (1986).

4. L. B. Pankratz, Thermodynamic Properties of Elements and Oxides, U.S. Bureau of Mines, Bulletin 672 (1982).

5. I. Johnson and P. S. Maiya, J. Mater. Res., 9 (3), p. 1337 (1994).

6. P. S. Maiya, R. Russel, D. S. Rao, A. S. Wagh, and R. B. Poeppel, J. Mater. Res., 8 (6), p. 1337 (1993).

7. S. Y. Cheng, S. L. Fu and C. C. Wei, Ceramics International, 15, p. 231 (1989).

8. M. W. Benecke, N. Olson, and J. A. Pask, J. Am. Ceram. Soc., 50 (7), p. 365 (1967).

9. J. Krautkramer and H. Krautkramer, Ultrasonic Testing of Materials, Springer-Verlag, New York (1983).

10. W. F. Brown, Jr. and J. E. Srawley, Plane Strain Crack Toughness Testing of High Strength Metallic Materials, Am. Soc. for Testing and Materials, STP 410, Philadelphia (Dec. 1967).

11. P. S. Maiya, S. M. Sweeney, L. A. Carroll, and J. T. Dusek, in Advances in Porous Materials, eds. S. Komarneni, D. M. Smith, and J. S. Beck, Materials Research Soc. Symp Proc., 371, p. 337 (1995).

12. R. Erck, J. Adhesion Sci. Technol., 8 (3), p. 885 (1994).

13. S. K. Dutta, A. K. Mukhopadhyay, and D. Chakraborty, J. Am. Ceram. Soc, 71 (11), p. 942 (1988).

14. D. P. H. Hasselman, Bull. Am. Ceram. Soc., 49, p. 1033 (1970).

15. S. R. Witek, G. A. Miller, and M. P. Harmer, J. Am. Ceram. Soc., 72 (3), p. 469 (1989).

16. A. G. Evans, D. Giling, and and R. W. Davidge, J. of Mater. Sci., 5, p. 187 (1970). 
17. D. W. Richerson, Modern Ceramic Engineering, Marcel Dekker, Inc., New York (1982).

18. Thermophysical Properties of High Temperature Solid Materials, ed. V. S. Touloukian, Purdue Research Foundation, Purdue U., 5 (1967).

19. P. F. Ziegler and J. J. Rausch, J. Mater. for Energy Systems, 8 (1), p. 49 (1986).

20. W. Weibull, J. Appl. Mech. 18, p. 293 (1951).

21. R. Sadananda, J. Mater. Res., 6 (1), p. 202) (1991).

22. K. Trustrum and A. De S. Jayatilaka, J. Mater. Soc., 14, p. 1080 (1979).

23. A. W. Mullendore and J. F. Smatana, TFTR Limited Study: Coating Adhesion Testing and Graphite Surface Preparation, Sandia National Laboratories, SAND85-1514 (Nov. 1985). 


\section{FIGURE CAPTIONS}

Figure 1. Schematic Diagram of Hot Press and Die Assembly.

Figure 2. Schematic Diagram of Pin-Pull Test Geometry.

Figure 3. Effect of $\mathrm{Li}_{2} \mathrm{CO}_{3}$ on Density of $\mathrm{TiN}$ at $1250^{\circ} \mathrm{C}$.

Figure 4. Young's Modulus vs. Porosity in TiN.

Figure 5. Shear Modulus vs. Porosity in TiN.

Figure 6. Strength vs. porosity in TiN.

Figure 7. Probability of Failure vs. Pull Stress for TiN-Coated Graphite.

Figure 8. Cross-Sectional SEM Photomicrographs of Graphite Coated with TiN Exposed to (a) $\mathrm{CaCl}_{2}-7$ wt.\% $\mathrm{CaO}$ and (b) $\mathrm{CaCl}_{2}-7$ wt.\% $\mathrm{CaO}$ saturated with $\mathrm{Ca}+\mathrm{Zn}$ $10 \mathrm{wt} . \% \mathrm{Mg}$. Exposure was at $800^{\circ} \mathrm{C}$ for $168 \mathrm{~h}$. 

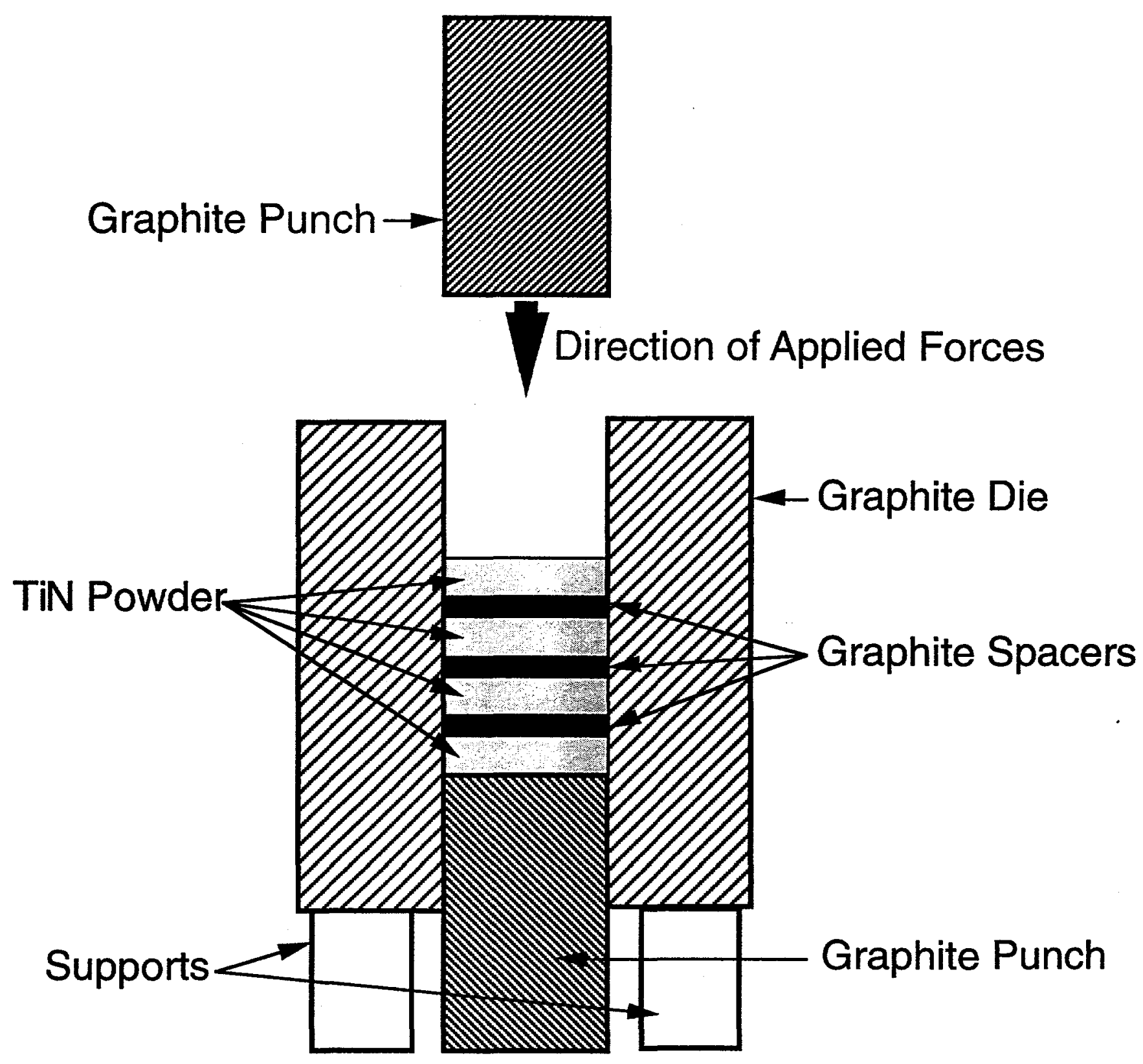

Figure 1. Schematic Diagram of Hot Press and Die Assembly. 


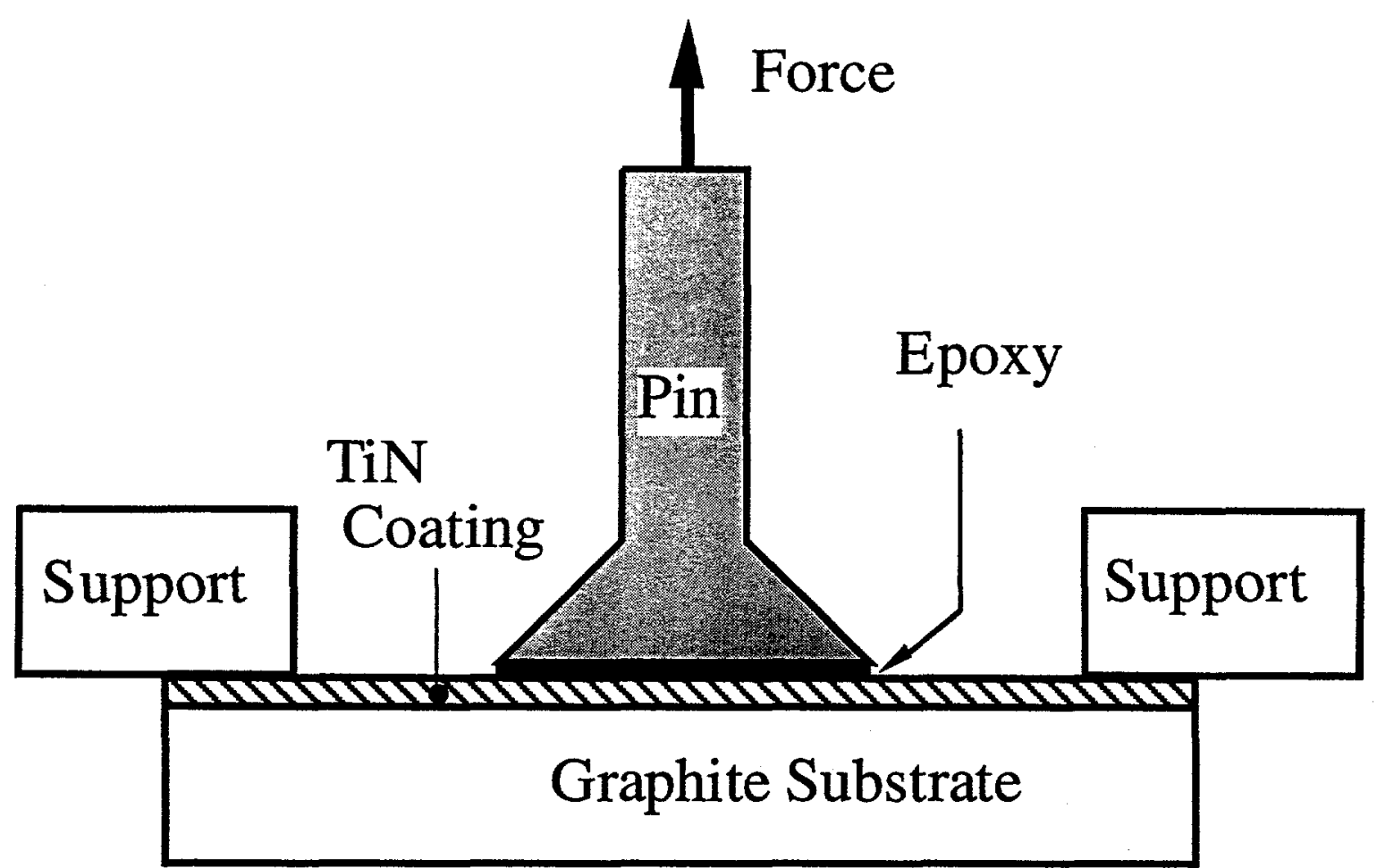

Figure 2. Schematic Diagaram of Pin-Pull Test Geometry.

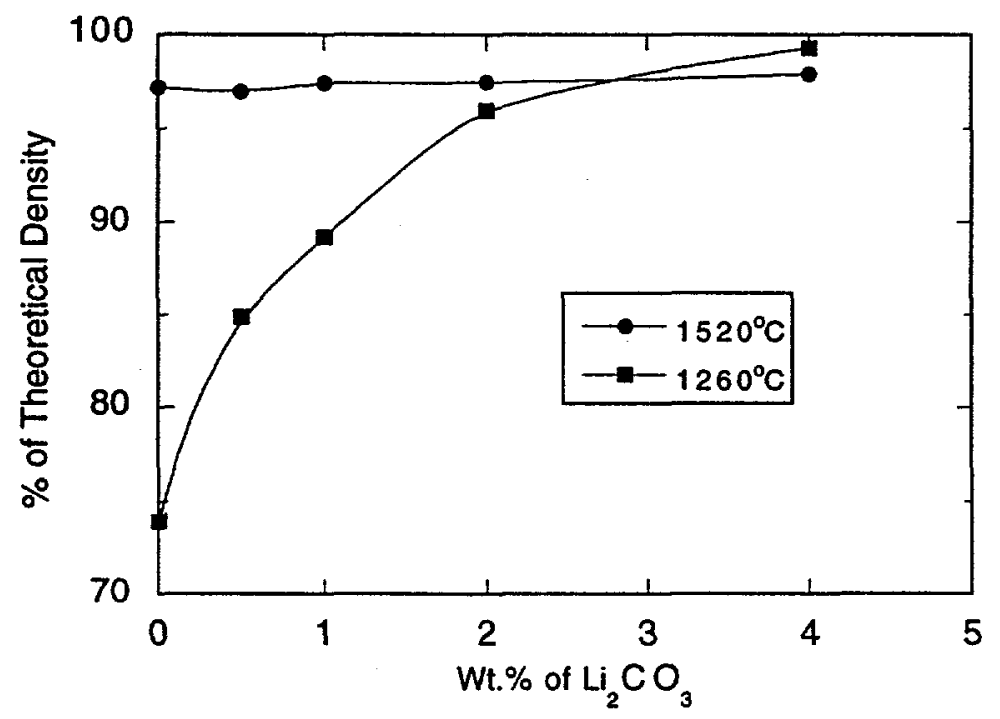

Figure 3. Effect of $\mathrm{Li}_{2} \mathrm{CO}_{3}$ on Density of TiN. 


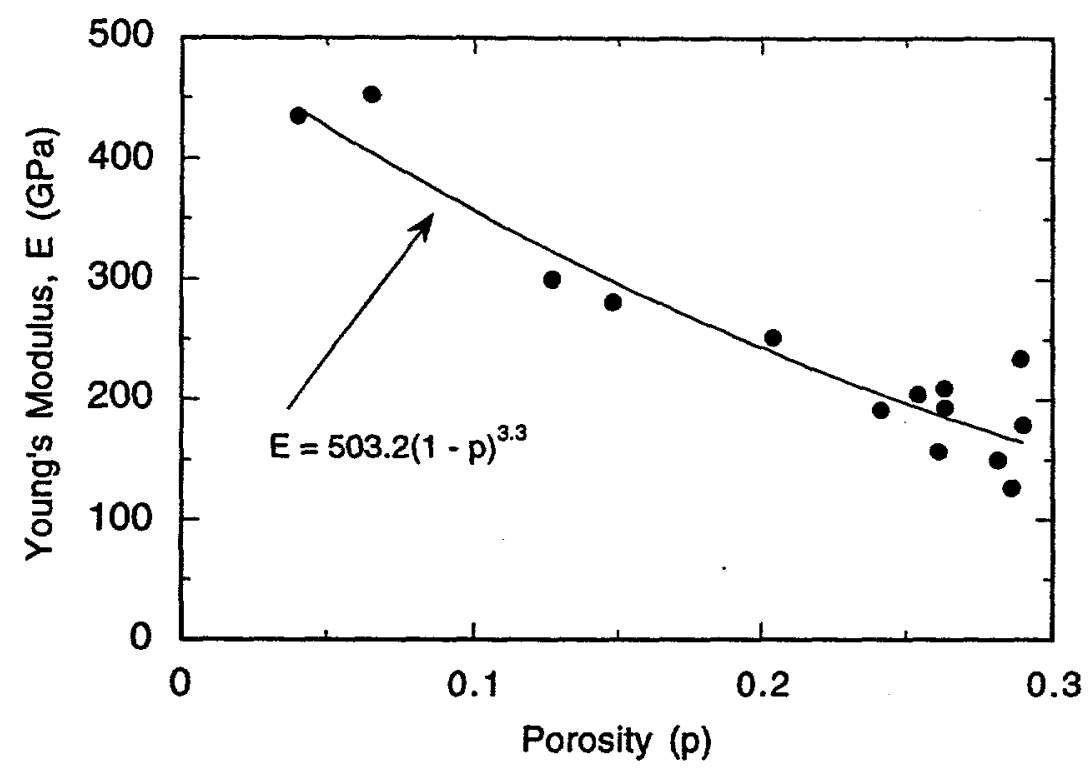

Figure 4. Young's Modulus vs. Porosity in TiN.

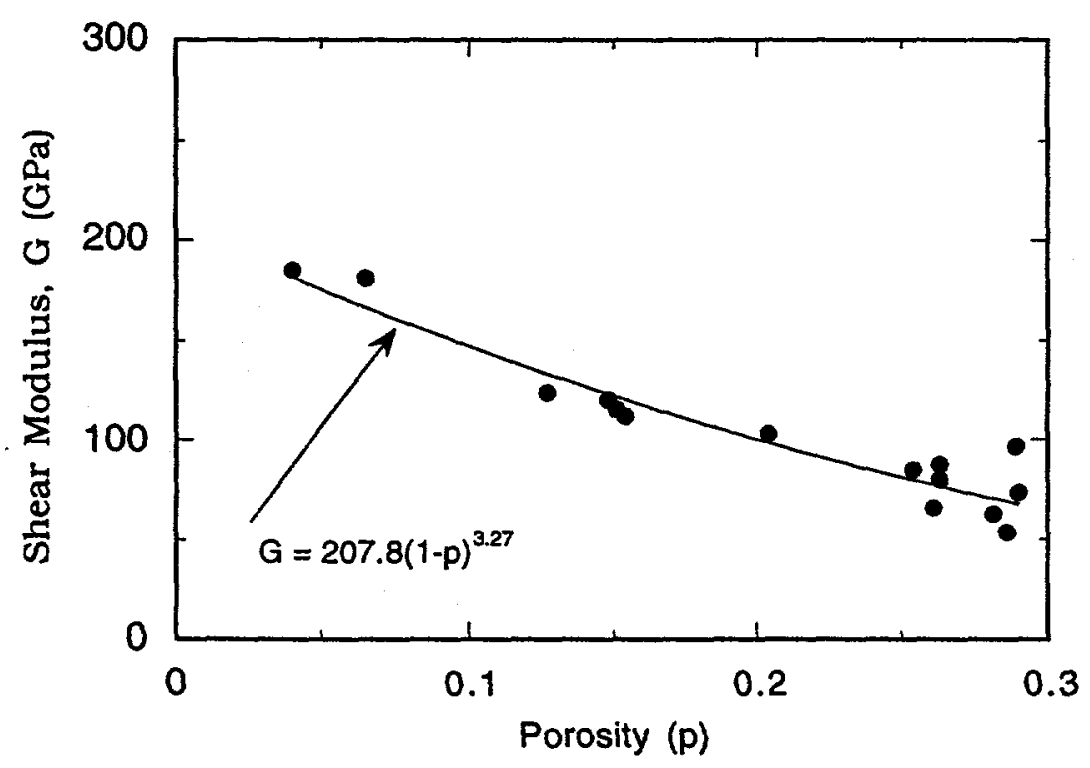

Figure 5. Shear Modulus vs. Porosity in TiN. 


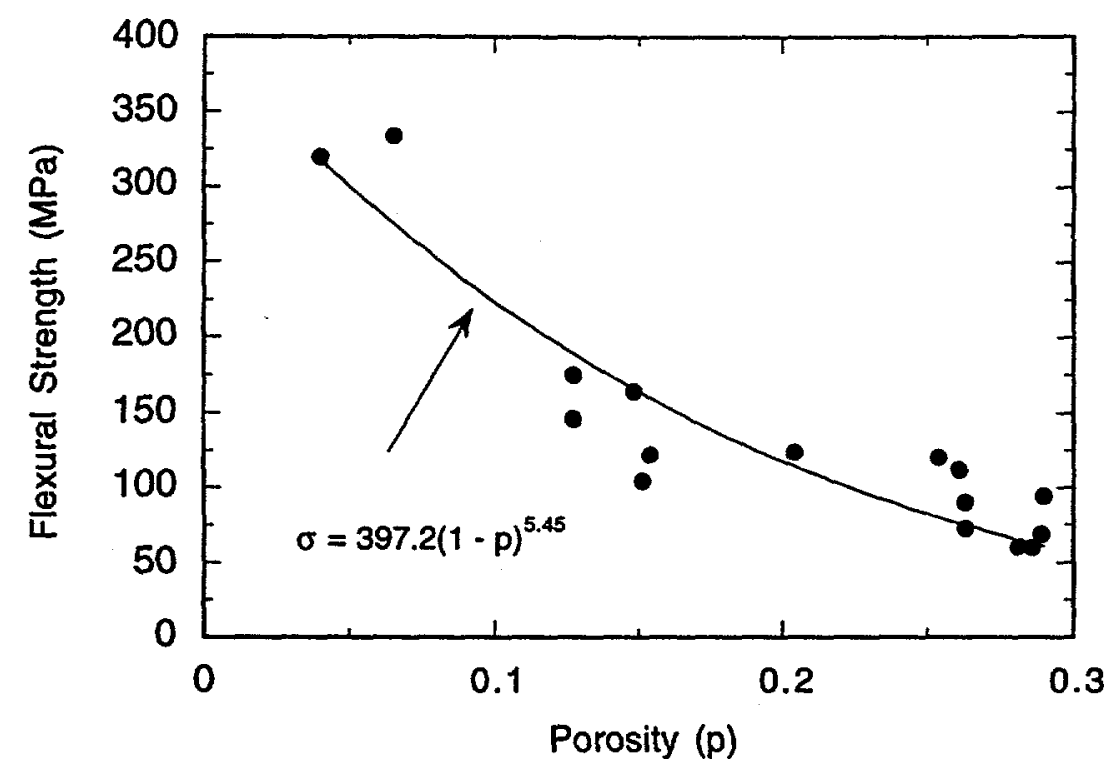

Figure 6. Strength vs. Porosity in TiN.

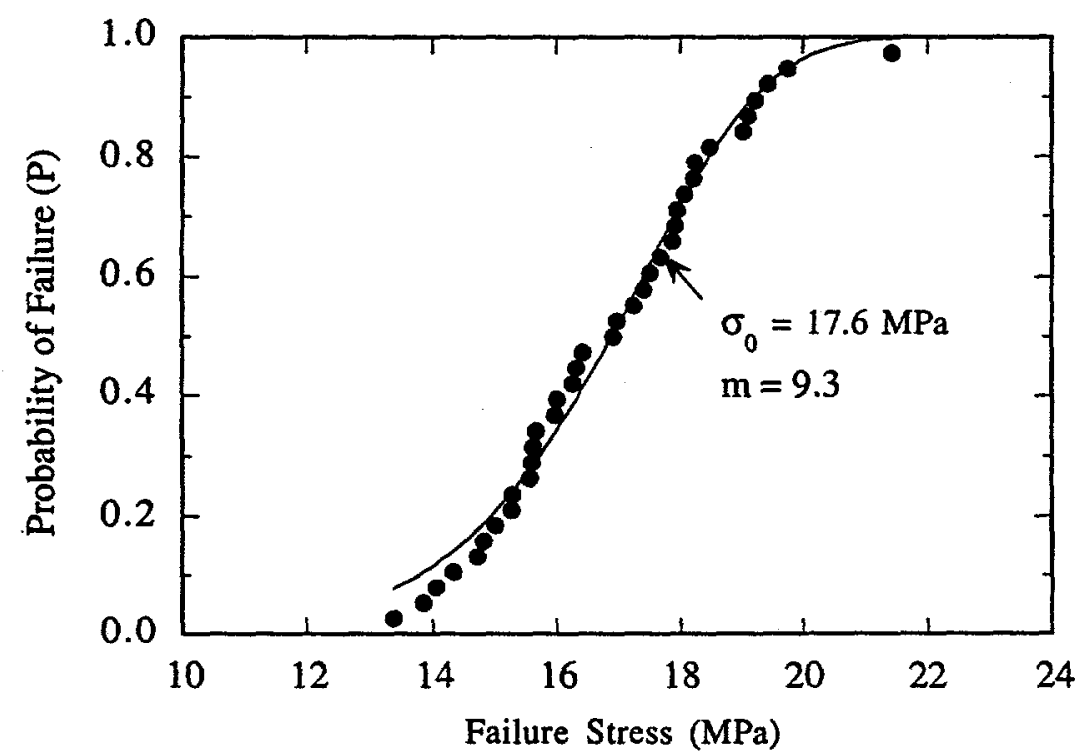

Figure 7. Probability of Failure vs. Pull Stress for TiN-Coated Graphite. 


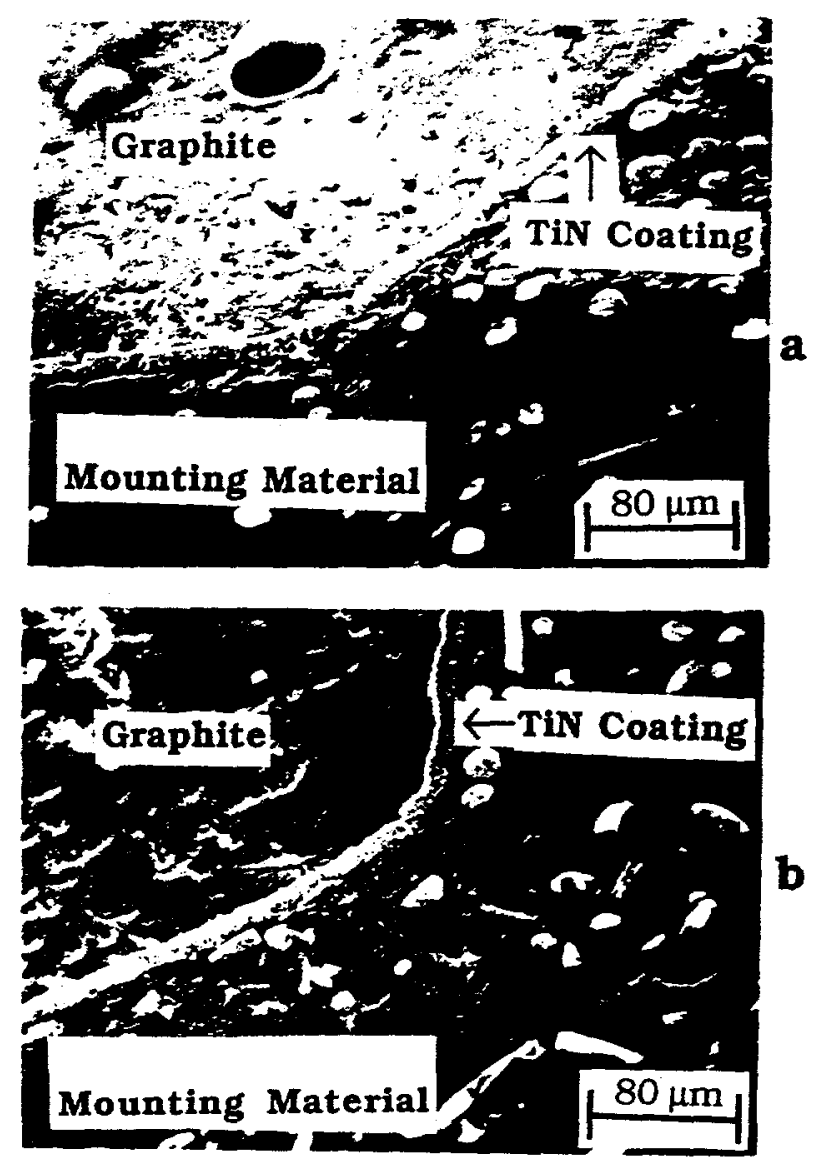

Figure 8. Cross-sectional SEM Photomicrographs of Graphite-coated with TiN Exposed to (a) $\mathrm{CaCl}_{2}-7$ wt. $\% \mathrm{CaO}$ and (b) $\mathrm{CaCl}_{2}-7$ wt. $\% \mathrm{CaO}$ saturated with $\mathrm{Ca}+\mathrm{Zn}-10$ wt.\% Mg. Exposure was at $800^{\circ} \mathrm{C}$ for $168 \mathrm{~h}$. 